\title{
Therapeutic encounters and the elicitation of community care
}

\section{Isteinko@gmail.com mdebarra@gmail.com}

Singh's analysis of shamanism is regarded as a contribution to the evolutionary study of healing encounters and evolutionary medicine. Shamans must create convincing healing spectacles, while sick individuals must convincingly express symptoms and suffering to motivate community care. Both have a shared interest in convincing onlookers. This is not restricted to shamanic treatment, but is still true in modern medical care.

Singh's work can be regarded as a useful contribution to the evolutionary science of healing developed by Fabrega decades ago (Fabrega 1997; Steinkopf 2017). One of Singh's (2017) main proposals is that those shamanic practices should succeed in the process of cultural evolution that create the strongest impression of effectiveness irrespective of actual effectiveness. This commentary extends this argument by arguing that both shamans and their patients are engaged in an act of joint persuasion: Shamans strive to convince others that their actions are effective therapies; patients strive to convince others in the community that they have a legitimate need for care.

The social environment of sick or injured humans is fundamentally different from the social environment of sick individuals of other species. In non-human animals, being 
recognized as sick or injured can lead to a loss of attractiveness as a mate or cooperation partner, to a challenge of social rank, to avoidance or exclusion from the group, or to preferential targeting by predators (Tiokhin 2016). Although all of this also could happen to sick or injured humans, a different response from the social environment is rare in other species and highly common in humans: social support and treatment (Steinkopf 2015). Ethnographic and archeological research has demonstrated that this kind of social support is essential for convalescence; disease and injury mortality would be markedly higher in its absence (Gurven et al. 2012; Navarrete \& Fessler 2006; Tilley 2015). Thus, patients must convincingly communicate their need for care to others in their communities. This has a number of implications for the evolution of health and healing: The prosocial environment of humans should favor symptoms that signal suffering convincingly and motivate others to acknowledge the sick state and grant help and treatment (Steinkopf 2015; 2017; Tiokhin 2016). Marked displays of pain in humans might be selected for their effectiveness in mobilizing others' support (Finlay \& Syal 2014; Steinkopf 2016; Williams 2002). Self-injury and suicidal behavior (Hagen 2008; Nock 2008) and the use of invasive and harmful treatments (de Barra \& Cownden 2016) have been hypothesized to serve as highly costly signals to convince others of the victim's neediness. Somatization can be regarded as a mechanism of changing the channel from psychological to somatic symptoms in an environment in which psychological symptoms would not be acknowledged (Brüne 2015; Kleinman 1986).

Thus, the community at large has an important role in the healing encounter. This group has to acknowledge the sick state to absolve the sick individual from tasks and 
responsibilities and to legitimize provision of food and care. An additional function of the shamanic intervention, therefore, may be to point to - and to convince others of - the fact that the focal individual needs care. In this context of cooperative caregiving, rituals that are dramatic or striking may be more effective in convincing others (de Barra \& Cownden 2016): Who but someone in true need of care would undergo such a treatment? The cultural selection pressures acting on the shaman thus may favor performances that inspire fear and trepidation. Formidable dress, contact with powerful forces, and simulated surgical interventions are culturally effective displays because they signal to others that the sick individual has a legitimate problem and need for care. In a sense, the role of the shaman may be diagnostic (reliability informing others of the patient's illness and care) as much as curative. Remarkably, both the sick individual and the shaman should have a shared interest in a convincing healing performance; a successful illusion of treatment effect and patient response supports both the shaman's claim of expertise and the patient's adoption of the sick role.

The aforementioned mechanisms of reciprocal communication and persuasion are not restricted to the environment of small-scale societies and shamans; they can still be observed in modern medical environments (Moerman 2002). Today, as before, sick individuals have to convince others of their need for care, and doctors (especially when self-employed) have to convince people of their competence and care (Steinkopf 2012; 2017). Further, the rituals and structure of contemporary medicine still play an important role in highlighting and legitimizing patients' need for care. Although health belief systems have largely changed from spiritual to biological, parallels between 
contemporary medicine and shamanism are evident. Although medical training no longer requires celibacy, the arduous and prolonged training can be considered a similarly transformative event. Interestingly, the duration of medical training in Western medicine has remained at six or seven years since medieval times at least, despite great differences in availability of useful biomedical knowledge (French 2003). Further, patients usually go to doctors with the expectation of receiving acknowledgment of their sick states by being prescribed treatments, often leading to the prescription of pure or impure placebos or even overtreatment (e.g., Faessler et al. 2010; Howick et al. 2013; Meissner et al. 2012). Although the prescribed treatment is ineffective or even harmful, it contributes to the legitimization of the patient's suffering as well as to the doctor's reputation. On the one hand, the doctor's acknowledgement of the patient's sick state manifested in diagnosis and prescription is a signal to the community for a legitimate need for relief and care. On the other hand, a doctor generously prescribing treatment and thus acknowledging the patient's needs may develop a better reputation (and more economic success) than a medical miser who treats only when treatment is indicated (Fabrega 1997; Steinkopf 2017).

In sum, the shaman has to persuade patients and onlookers through a healing spectacle, and the sick individual has to convince others of a sick state, incapacity, and a need for care. Both may have a shared interest in making the healing encounter appear effective, because it supports the shaman's claim of expertise and the patient's adoption of the sick role. Modern doctors also act and compete in terms of satisfying expectations and building community consensus around the sick person's need for care. 
$<$ C-text ends $>$

$<$ RFT $>$ References [Leander Steinkopf and Mícheál de Barra] $<$ REFS $>$

Brüne, M. (2015) Textbook of evolutionary psychiatry and psychosomatic medicine: The origins of psychopathology, second edition. Oxford University Press.

De Barra, M. \& Cownden, D. (2016) Medicine as message: Caregiving, illness deception, and the cultural evolution of harmful treatments. Open Science Framework Preprint. Available at: https://osf.io/mxyts/

Fabrega, H. (1997) Evolution of sickness and healing. University of California Press.

Faessler, M., Meissner, K., Schneider, A. \& Linde, K. (2010) Frequency and circumstances of placebo use in clinical practice: A systematic review of empirical studies. BMC Medicine 8:15. doi:10.1186/1741-7015-8-15.

Finlay, B. L. \& Syal, S. (2014) The pain of altruism. Trends in Cognitive Sciences 18(12):615-17. doi:10.1016/j.tics.2014.08.002.

French, R. K. (2003) Medicine before science: The business of medicine from the Middle Ages to the Enlightenment. Cambridge University Press.

Gurven, M., Stieglitz, J., Hooper, P. L., Gomes, C. \& Kaplan, H. (2012) From the womb to the tomb: The role of transfers in shaping the evolved human life history. Experimental Gerontology 47(10):807-13. doi:10.1016/j.exger.2012.05.006.

Hagen, E. H., Watson, P. J. \& Hammerstein, P. (2008) Gestures of despair and hope: A view on deliberate self-harm from economics and evolutionary biology. Biological Theory 3(2):123-38. doi:10.1162/biot.2008.3.2.123. 
Howick, J., Bishop, F. L., Heneghan, C., Wolstenholme, J., Stevens, S., Hobbs, F. D. R. \& Lewith, G. (2013) Placebo use in the United Kingdom: Results from a national survey of primary care practitioners. Plos One 8(3):e58247. doi:10.1371/journal.pone.0058247.

Kleinman, P. A. (1986) Culture and depression: Studies in the anthropology and crosscultural psychiatry of affect and disorder, revised edition (comparative studies of health systems and medical care). University of California Press.

Meissner, K., Höfner, L., Fässler, M. \& Linde, K. (2012) Widespread use of pure and impure placebo interventions by GPs in Germany. Family Practice 29(1):79-85. doi:10.1093/fampra/cmr045.

Moerman, D. E. (2002) Meaning, Medicine and the "Placebo Effect." Cambridge University Press.

Navarrete, C. D. \& Fessler, D. M. T. (2006) Disease avoidance and ethnocentrism: The effects of disease vulnerability and disgust sensitivity on intergroup attitudes. Evolution and Human Behavior 27(4):270-82. doi:10.1016/j.evolhumbehav.2005.12.001.

Nock, M. K. (2008) Actions speak louder than words: An elaborated theoretical model of the social functions of self-injury and other harmful behaviors. Applied and Preventive Psychology 12(4):159-68. doi:10.1016/j.appsy.2008.05.002.

Singh, M. (2017) The cultural evolution of shamanism. Behavioral and Brain Sciences 1-83. doi:10.1017/S0140525X17001893. 
Steinkopf, L. (2012) Enhancing drug compliance and the placebo effect by raising subjective expectations. Medical Hypotheses 79(5):698-700.

doi:10.1016/j.mehy.2012.08.011.

Steinkopf, L. (2015) The signaling theory of symptoms: An evolutionary explanation of the placebo effect. Evolutionary Psychology 13(3):1474704915600559. doi:10.1177/1474704915600559.

Steinkopf, L. (2016) An evolutionary perspective on pain communication. Evolutionary Psychology 14(2):1474704916653964. doi:10.1177/1474704916653964.

Steinkopf, L. (2017) The social situation of sickness: An evolutionary perspective on therapeutic encounters. Evolutionary Psychological Science 3(3):270-86. doi:10.1007/s40806-017-0086-8.

Tilley, L. (2015). Theory and practice in the bioarchaeology of care. Springer International Publishing.

Tiokhin, L. (2016) Do symptoms of illness serve signalling functions? (Hint: Yes). Quarterly Review of Biology 91(2):177-95.

Williams, A. C. de C. (2002) Facial expression of pain: an evolutionary account. Behavioral and Brain Sciences 25(4):439-55. 